\title{
THE UNIVERSAL DECISION - APPROPRIATE DESIGN FOR HERITAGE OBJECTS
}

\author{
Dimitar Dobrevski \\ National Academy of Visual Arts, Sofia, Bulgaria \\ ddobrevski@gmail.com
}

\begin{abstract}
Discussing the universal decision of the design for everybody - this paper introduces one of the most actual problems of contemporary exterior and interior industrial design - the designing not only ergonomic, but specifically - for disabled or impaired people, regarding their access to heritage objects. The presented ideas are inspired by the research of University of Carolina, and based on my experience in creating and teaching in National Academy of Arts, where BA Program is training students to design for children, and MA program is devoted to development of the skills of industrial designers to face the necessities of disabled people.
\end{abstract}

Keywords: Utilitarian Art; Universal Decision; Cultural-Historical Heritage; Design for Disabled People

\section{УНИВЕРСААНОТО РЕШЕНИЕ - ПОАХОАЯЩ АИЗАЙН ЗА ОБЕКТИ НА КУАТУРНО- ИСТОРИЧЕСКО НАСАЕАСТВО}

\author{
$\triangle$ Амитьр Аобревски \\ Национална художествена акалемия, Софрия, България
}

Резюме: Съотнасянето на темата за подходящия Аизайн за обекти на културно-историческото наслеАство Към Универсалното решение на Аизайна Аостьен за всички, този АокАаА разглежАа еАин от най-актуалните проблеми на съвременния интериорен и екстериорен Аизайн - ергономично издържаното проектиране на предметна и архитектурна среАа за хора с уврежАания и специални потребности. Представените илеи са вАъхновени от проучване на Университета на Каролина и основани на опита от творчеството и преподаването ми в Националната художествена акацемия, където бакалавърска програма обучава студентите Аа съзАават Аизайн на Аетската среда, а магистьрска програма е посветена на квалифрицирането на индустриалните дизайнерибакалаври Аа посрещат потребностите на хората с уврежАания.

КАючови Ауми: утилитарно изкуство, универсално решение, културно-историческо наслеАство, Аизайн за хора с уврежАания 


\section{Въведение.}

Напоследьк е особено актуално да се коментира приобщаването на обекти от градската среАа към еАна немалка част от българското общество - хората с уврежАания или Аруги Аефрицити. Това в еАна голяма степен е валиАно и по отношение на обектите на КИН. Те са посетени и от много чужАенци, които туристи или специалисти, понякога също попалат в тази група. Голям е Аельт и на хората в напреднала възраст, които в много отношения са затруднени също функционално и Авигателно.

Външно това се забелязва най-много по реконструкцията на крьстовищата и тротоарите, звуково индицираните светофрари и пуснатите трамвайни мотриси с централна снижена рампа, по-удобна за ползване от ^ица в инвалиАни колички и от възрастни хора.

Все още незабележими остават някои Аруги инициативи произтичащи от приетата „НареАба за изгражАане на общодостьпна среда в София", която в голяма степен е последвана от аналогични инициативи и в останалите български селища. Тази наредба е насочена към преололяване на проблемите на еАна значителна част от българското население (за съжаление все още статистиката полава противоречиви Аанни за техния Аействителен брой).

Аълго време отношението на обществото към хората с уврежлания е така $\Delta$ а се каже енна позорна страница от Всемирната история, която бележи своите паления и кулминации. Колкото по-назаА се връщаме, толкова по-безучастно е отношението към хората с уврежАания, особено вродени. Човешкият живот често не е струвал Аори пукната пара. Фрапиращ е примерьт с Аревна Спарта, когато бебета дори и с най-малки отклонения са били хвърляни в близката пропаст и Терпейската скала се е превърнала в учебникарски пример. Полобен краен геноциА към хората с уврежлания се повтаря по време на Третия райх, когато в името на чиста раса стотици хиляАи са изпратени в концентрационните лагери и хи^яАи хора с ментални уврежАания са миквидирани и дори кастрирани. Тогава на практика няма инвалиАИ, защото обществото просто се освобожАава от тях.

Особен етап е времето на Европейското Средновековие, когато се появява ново отношение към хромите и сакатите. Спецификата е предопределена от християнския мистицизъм. Той им отАеля 
съществена роля в обществените отношения, опираща се на $А$ ва opakta:

о Вярва се, че Бог стоварва върху ^юбимците си изпитания, бели и болести. Недьгьт е особен знак, показващ Неговото внимание и Неговата ^юбов. НеАъгът е знак за Благословия.

О В същото време еАни от най-цитираните Ауми на Исус са били: „Аайте и ще ви се $\Delta$ але!"

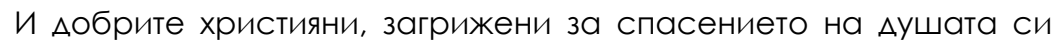
Аавали ми^остиня на носещите „знака", за да измолят чрез тези Божии посреАници милост за себе си и спасение на Аушата си. Затова и

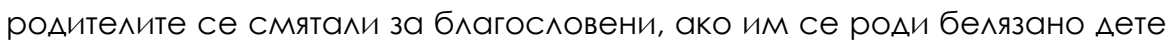
- хромо или сакато.

Образът на инвалида - такъв, какъвто ни го преАставяха Аоскоро - ce ражАа преди около 250 голини по време на Инаустриалната революция, почти успореАно със зараждането на Аизайна, (поне спореА еАна от най-често разпространените теории за неговото възникване). Тогава мистиката на християнството бива Аоста безцеремонно изместена от необхолимостта и прагматизмьт на времето, като трьгнем от манифрактурата и стигнем Ао модерното инАустриално производство (Velev, 1995).

Краят на 19 век поражАа условията, в които хората с някакви ффизически деффицити се превръщат в „инвалиАи" т.е. невалиАни. През този периол производството на стоки е изисквало всеки работник Аа има зАрави крайници, сетива и психика. Аипсата на само еАно от тези условия е пречела на реализацията в индустриализираното общество и на практика е изключвала не само от участие в производствения процес, но и от пьлноценна роля във всички Аруги форми на нормално общуване.

Обектите на КИН труАно могат Аа се подвеАат пол еАин общ знаменател, но безспорен е фоактьт, че важно условие за тяхното социализиране е изгражлане на пространствено Аизайнерско решение и тяхното социализиране и алаптиране към човешките потребности. На прьв поглед залачата: средата $ы$ а се алаптира еАновременно за потребностите на по-голямата част от посетителите без деорицити и към специфоичните изисквания за хора с уврежАания, изглежАа нерешима, но в редица волещи страни в света вече упорито се търсят решения и има разработени методични инструменти за Аизайнерско проектиране на средата и редица продукти. 
Из^ожение. В нашето общество все още преобладава нетолерантно отношение и неразбиране на природата на уврежАанията. ЕАин от начините за преололяване на това

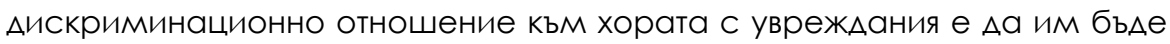
осигурена възможност за Аостьп Ао всички сорери на социалното битие - Ао цялата гралска инорраструктура и културни институции, а това не може $а$ мине и без участието на мизайнерите като творци на непосредственото обкрьжение на човека - утилитарната среда.

Преди 15 години - 2005 гол. беше обнародван еАин нов законопроект - „Закон за интеграция на хората с уврежАания”, който с появяването си се възприе като панацея и поне в началото съз $а$ але впечатлението, че всички проблеми на хората с уврежлане са вече решени.

За съжаление в България засега липсва точна статистика по този проблем. (СпореА Социалното министерство инвалидизираните мица са Около 500 000), но изслеАванията в редица европейски страни показват, че хората с уврежлания са почти 20 \% от цялото население и тенленцията е този процент $а$ а нараства, порали увеличението на възрастните хора, спрямо населението като цяло.У нас основният брой уврежАания иАва от з^ополуки в произво Аствената среАа и транспортни инциленти, Аокато тези С вродени Аефрормация са сравнително незначителен процент (еАва1500 на 150000 ражАания - 1980 гоА.). Трябва да се отбележи фракта, че в същото време 30000 Ауши годишно стават инвалиАи от злополуки за прьв пьт. На по-кьсен етап статистика е водена само за хората в инвалиАни колички и на практика Анес не се знае истинския брой на лицата с различни уврежАания.

ИнвалиАността е пряко свързана с увеличението на възрастта $70 \%$ от хората с уврежАания са на възраст наА 45 голини. В България пенсионерите, които вече са повече от 2 милиона, получават вторични затруднения, свързани с Авижението, зрението или слуха, Аьлжащи се на естествения процес на стареене. В живота си повечето хора получават временни уврежАания, вследствие на заболявания или травми Аори в много ранна възраст. Универсалната Аостьпност на средата и продуктите на Аизайна служи не само на хората с уврежАания, но също така улеснява всекиАневния живот на хората с малки Аеца и на самите меца. Например четливите и лесно разбираеми знаци на 
визуалната комуникация улесняват всекилневния живот не само на хора с ментални уврежлания, но и на малките деца и хора, които не разбират Аобре местния език или азбука.

Какво е отношението на Аизайнерите към този проблем? Още на Осмия конгрес на ИКСИА в Япония (1973 гоА.) тези въпроси бяха формулирани за прьв пьт на Аизайнерски форум, като еАни от найприоритетните и важни за дизайна в съвременния етап на развитие.

Проблемът беше поставен и на други форуми - Юнеско, семинар „Интерлизайн” в Харков, Полша, при участието на Аизайнери от 12 страни, конфреренция в Израел на тема „Аизайн за инвалили" 1980г. В България 1981 година беше обявена официилно за голина на хората с уврежАания. СлеА това послеАва еАин относително Аьльг периол на безлействие, но Анес слеА промените вече съществуват повече от 20 неправителствени саружения на хора с увреждания и се отбелязва Аори деня на световна солидарност с хората с уврежАания 30 ноември.

Съществуват няколко основни трудности за приобщаването на проектантите на среАата (ВкАючително и тази на обектите на КИН):

1. Проблемите на хората с уврежлания са толкова разнообразни и специорични, колкото са и самите уврежАания.

2. Наличната инорормация е Аоста противоречива, оскъАна и труАно може $\Delta$ а се ползва без натрупване на познания, които са Аоста отАалечени от Аизайна.

3. Тази проблематика е трудно съвместима с основната програма.

4. Проектирането има смисъл, ако илеите се реализират, а това е труАно осъществимо.

5. Аипсва метоАично РъковоАство.

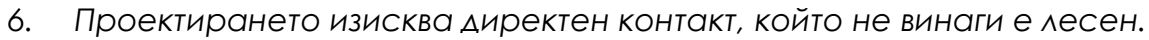

7. Съществува силна психологическа бариера, която налага на първо място ние самите Аа променим мисленето си.

8. Самите хора с уврежАания също трябва $а$ а извъвят своята част от Пътя.

НужАите на хората с уврежАания правят по-всеобхватни много решения за Аостьпността. Всичко това визира еАин проблем с глобален характер, имащ пряко или косвено отношение към всички членове на обществото. Този проблем, осъзнато или неосъзнато, у нас реолектира еАно пьлно неразбиране на същината си дори от специалистите. 
Понякога има и допьлнителни затруднения, свьрзани с обстоятелството, че възрастните хора, които трудно се приАвижват, често оспорват фракта, че са „инвалиАи”, а м^аАи хора в инвалиАни Колички отказват Аа бъАат поставяни в еАна категория с възрастните.

Универсалното решение се базира на разбирането, че хората имат различни възможности и това трябва да намери отражение, както в процеса на проектиране, така и в крайния продукт. Тук с пьлна сила и особено актуално може $а$ а се при^ожи Аевиза - „проектираме собственото си бъдеще" (Mitreva, 2000).

НужАите на хората с ффизически уврежлания, особено на ползващите инвалиАни колички, се вижАат ^есно. Независимо от това обществото в световен мащаб Аостигна Аоста късно - чак в края на XX век/ Ао тези илеи. През 90те години в САЩ бе приет закона ADA /The Americans with disability act/ - "Закон за американците с уврежАания", с който бе защитено за прьв пьт равноправното отношение и равнопоставеността на всички членове на обществото.

Грижите за хората с уврежАания заемат централно място в осъществяването на илеята за „Универсалното решение”. Те трябва обаче $\Delta а$ бълат обвьрзани и с грижа за цялото останало население, би^о то Аеца, възрастни или хора с различен етнически произхол или култура. ИАеята за „Универсалното решение” ни помага Аа мислим погъвкаво и Аа разглежАаме фризическото, икономическото и социално планиране като взаимно свързани елементи. "Универсалното решение" представлява съзАаване и съчетаване на различни продукти и среда, които Аа бъдат ползвани от всички хора в най-голяма степен, без необходимост от алаптация или специализирано проектиране.

Основните принципи на „Универсалното решение” са разработени от „Центьр за универсални решения" в Университета на щата Северна Каролина. Те в най-общи линии гласят:

1. Справедливо ползване.

2. Гъвкавост при ползването.

3. Аесно и интуитивно ползване.

4. Толерантност кьм грешките.

5. Аесна за възприемане инорормация.

6. Неголеми оризически усилия.

7. Свободни размери и пространство за подхол /ползване/. 
Приложението на това решение е амбициозна и благородна залача, която изисква Аетайлно познаване на проблемите. Необхолими са повече усилия в изследователската и развойна Аейност, но за съжаление у нас този проблем стои все още встрани от вниманието на архитектите и Аизайнерите.

ЕАна от основните причини за неглижирането на проблема е потресаващо ниския станАарт на живот в Бьлгария, но и неАостатьчното отАелено внимание кьм този проблем от учебните заведения обучаващи архитекти и Аизайнери. В голяма степен инертно се Аьржат и не правителствените организации имащи отношение кьм проблемите на хората с увреждания.

Предизвикателство е преминаването от теория кьм практика, с вкАючване на всички групи потребители в планирането и иизайнпроектирането. В това отношение може да почерпим опит от редица европейски Аьржави, в които напредва работата по изграждането на инструментариум, чрез който $\Delta a$ ce подобрят стандартите. С приемането на „Наредбата за изграждане на общолостьпна среда в гр. Софрия", ние сме направили само пьрвата крачка в правилната посока. Трябва Аа се извьрви целия пьт

\section{Заключение.}

Необходимо е по-широко обществено участие. Принос в тази посока е програмата на секция „Аизайн” в СБХ, която вКАючва организирането на изложби и конкурси (ОХИ „Опит за летене - Аизайн за всички" през месец юли 2003 гол. в залите на Националния изложбен центьр - ул. Шипка \#6 в Соория, конкурс за естетизация на градската срела). Тя визира проектни решения на профресионалисти Аизайнери и студенти в НХА, АСТУ и ТУ - Софрия. Проектите на участниците са насочени кьм решаване на проблемите на тази част от нашето болно общество, която най-трудно понася несгодите на средата - хората с уврежАания, възрастните и децата. Много често тези немалки групи от нашето общество са поставени в крайно неравностойно положение и сами не могат $а$ а направят нищо за Аа си помогнат.

Амбициозно е включването на проблема в учебната програма на магистьрската степен от катеАра „ИнАустриален Аизайн” при НХА.

Разработено е метолическо рьководство за Аизайнерско проектиране на средата и продуктите, балансиращо межАу принципите на Универсалното решение и сьобразяване с по-тесни 


специфични изисквания, съобразени със специфриката на
уврежАанията на отАелни групи хора.

Принципите на „Универсалното решение” са особено приложими в областта на Аизайна, въпреки че промишленият Аизайн е Аоста всеобхватна Аисциплина, която трудно може $а$ бъле обвързана само с няколкото изброени принципа.

Аизайнерите и производителите обаче трябва да приемат преАизвикателствата на „Универсалното решение”, очертало се като межАународна тенденция, която в близко бъдеще може $\Delta а$ се окаже императивно зальлжителна. „Универсалното решение” е отговор на редица важни социални предизвикателства. То сьдьржа в себе си генералния подхоА на планиране и проектиране в областите на архитектурата и Аизайна. То не налага "илеална форма" и зальлжителни насоки.

Функционалността на „Универсалното решение” е приложима заедно с повечето Аруги елементи на художественото проектиране като фрункционаАност естетичност, икономичност и социалност. То поставя фуунаментални залачи за връзка межАу теория и практика, метоли и приложност. Открити са много възможности и поле за еАна сериозна Аискусия по въпроса. Наложително е $а$ се ангажират както правителствени така и обществени, частни слружения, фрирми и образователни учрежления.

\section{AИTEPATYPA / REFERENCES}

Velev, P. (1995). Proektirane i izgrazhdane na zhiznenata sreda za invalidi (in Bulgarian). In Arhitekturen spravochnik. Publisher: SAB, Sofia, Bulgaria // [Велев, П. (1995). Проектиране и изгражАане на жизнената среда за инвалили: Архитектурен справочник. САБ, Софиия].

Mitreva, E. (interpreter) (2000). Universalnoto reshenie - planirane i dizajn za vsichki: Spravochnik na proektanta, stroitelya i investitora (in Bulgarian). Publisher: Arh Art, Sofia, Bulgaria, 2000, ISBN: 954-8931-08-7 [Universal Solution, https://cil.bg/wpcontent/uploads/2020/03/universal_solution.pdf, (Last view: 07.03.2020)] // [Универсалното решение - планиране и Аизайн за всички: Справочник на проектанта, строителя и инвеститора. ISBN: 954-8931-08-7, Сосрия, 2000, Арх Арт, 2000 [Б. Р. Конел и кол., съставители. Центьр за универсални решения. Университет Северна Каролина, 1995]].

Основни законопроекти с отношение към хората с уврежАания / Major draft laws relating to people with disabilities:

Закон за интеграция на хората с уврежАания / Law on Integration of People with Disabilities. [https://www.noi.bg/images/bg/legislation/laws/ZIXY-otm.pdf, (Last view: 07.03.2020)]. 
Закон за защита, рехабилитация и социална интеграция на инвалидите / Law on Protection, Rehabilitation and Social Integration of Disabled Persons. -

[https://www.lex.bg/laws/ldoc/2135491478, (Last view: 07.03.2020)].

Закон за защита срещу Аискриминация / Anti-Discrimination Act. [https://www.lex.bg/laws/ldoc/2135472223, (Last view: 07.03.2020)].

Закон за социално полпомагане / Social Assistance Law. [https://www.lex.bg/laws/ldoc/2134405633, (Last view: 07.03.2020)].

Закон за военноинвалияите и военнопостраАалите / Law on war disabled and war injured. [https://www.lex.bg/laws/ldoc/2135501152, (Last view: 07.03.2020)].

закон за зАравното осигуряване / Law on Health Insurance. [https://www.lex.bg/laws/ldoc/2134412800, (Last view: 07.03.2020)].

Закон за семейните помощи / Family Allowances Act. [https://www.lex.bg/laws/ldoc/2135441920, (Last view: 07.03.2020)].

Закон за закрила на детето / Child Protection Act. - [https://www.lex.bg/laws/ldoc/2134925825, (Last view: 07.03.2020)].

Кодекс на труда / Labour Code. - [https://www.lex.bg/laws/ldoc/1594373121, (Last view: 07.03.2020)].

Кодекс за социално осигуряване / Code of Social Security. [https://www.nssi.bg/images/bg/legislation/Codes/KCO.pdf, (Last view: 07.03.2020)].

Интернет източници / Internet sources:

Столичен общински съвет. (2000). Наредба за Столичен общински съвет за изгражАане на общодостьпна среда в грал Софрия / Metropolitan Municipal Council. (2000). Ordinance for the Metropolitan Municipal Council for the construction of a generally accessible environment in the city of Sofia - [https://sofia.obshtini.bg/doc/105032, (Last view: 07.03.2020)]

Информационен портал за хора с уврежАания / Information portal for people with disabilities. - [http://www.aepid.org, (Last view: 07.03.2020)].

Общество „ААаптация“. (2020). Порта^ за психично зАраве: „Няма зАраве без психично зАраве!" / Adaptation Society. (2020). Mental Health Portal: "There is no health without mental health!" - [http://www.psihichnozdrave.com, (Last view: 07.03.2020)].

Център за независим живот - България / Center for Independent Living - Bulgaria. [http://www.cil-bg.org, (Last view: 07.03.2020)].

European Disability Forum (EDF). - [http://www.edf-feph.org, (Last view: 07.03.2020)].

Independent Living USA. (2020). - [http://www.ilusa.com, (Last view: 07.03.2020)].

Disability Now. (2020). Broadcasting and Media Production Company. Facebook Page "for, by and about disabled", Local Business, 2 October 2012, 9,873 like, 11,649 people follow, last post from 2018. - [https://www.facebook.com/DisabilityNow/, (Last view: 07.03.2020)].

Mountain State Centers for Independent Living. (2020). - [http://www.mtstcil.org, (Last view: 07.03.2020)]. 


\section{КУАТУРНО-ИСТОРИЧЕСКО НАСАЕАСТВО: \\ ОПАЗВАНЕ, ПРЕАСТАВЯНЕ, АИГИТААИЗАЦИЯ}

\section{CULTURAL AND \\ HISTORICAL \\ HERITAGE}

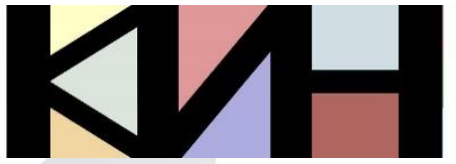

PRESERVATION PRESENTATION DIGITIZATION
Материалите в сборника са обект на авторско право. Разрешава се безвъзмезАното ползване на техни електронни/ хартиени копия само за лична употреба или обучение, при пь^но цитиране на текущата страница и слеА писмена декларация от цитиращия за Аипса на търговски намерения. За копиране пол Аруга фрорма, препубликуване или публикуване на сървъри се изисква писмено разрешение и/или заплащане.

() Авторски колектив, 2020 Техническо реАактори: Николай Ноев Калина Сотирова-Вълкова
This work is subject to copyright. Open and free of charge use of digital/hard copies of publications is granted only for personal or educational use, with full citation of the current page, and after written declaration of the quoting side for not-commercial Intention. For any other reproducing types, republishing, photocopying, recording, or any other storage retrieval system/ server written permission and/or fee is required.

(C) Authors` Group, 2020

Technical editors:

Nikolay Noev

Kalina Sotirova-Valkova

\section{Научна пореАица: том 6, брой 1 (8)/2020 Science series: vol. 6 , issue $1(8) / 2020$}

